Научная статья

УДК 332.1

DOI 10.18101/2304-4446-2021-1-10-20

\title{
МЕТОДОЛОГИЧЕСКИЕ ПОДХОДЫ К ДИАГНОСТИКЕ И ПРОГНОЗИРОВАНИЮ РАЗВИТИЯ РЕГИОНАЛЬНЫХ ПЕРСПЕКТИВНЫХ ЭКОНОМИЧЕСКИХ СПЕЦИАЛИЗАЦИЙ
}

\author{
(c) Аверина Лидия Михайловна \\ младший научный сотрудник \\ laverina@mail.ru
}

(C) Никулина Наталья Леонидовна

кандидат экономических наук, старший научный сотрудник

nikulinanl@mail.ru

Институт экономики УрО РАН

Россия, 620014, г. Екатеринбург, ул. Московская, 29

\begin{abstract}
Аннотация. В статье обоснована значимость развития новых отраслей региональной специализации с учетом глобальных вызовов технологического развития. Гипотезу исследования составляет предположение о важности роли перспективных и эффективных региональных отраслей специализации в трансформации хозяйственной структуры региона, обеспечивающей на инновационно-технологической основе новое качество экономического роста, усиление интегрированности в российское экономическое пространство. Рассмотрены основные подходы к определению роли региональных экономик в обеспечении конкурентоспособности страны. Отмечена значимость концепции умной специализации в прогнозировании развития региональных перспективных экономических специализаций. Определено, что для выделения перспективных экономических специализаций необходимы вариативный анализ особенностей формирования новых конкурентных отраслей специализации в соответствии с типами регионов; оценка наличия сквозных технологий межотраслевого значения на предприятиях, дислоцированных в разных регионах РФ, и возможной перспективы их кооперационного взаимодействия.

Ключевые слова: отрасли региональной специализации; региональные перспективные экономические специализации; конкурентоспособность; концепция умной специализации; диагностика; прогнозирование; ниши региональной экономики; межрегиональное взаимодействие.
\end{abstract}

\section{Для цитирования}

Аверина Л. М., Никулина Н. Л. Методологические подходы к диагностике и прогнозированию развития региональных перспективных экономических специализаций // Вестник Бурятского государственного университета. Экономика и менеджмент. 2021. № 1. C. $10-20$.

\section{1 Введение (актуальность исследования)}

В современных социально-экономических условиях возрастает роль региональной компоненты. Глобальная конкурентоспособность стран в настоящее время во многом обеспечивается за счет концентрации на отдельных территори- 
Л. М. Аверина, Н. Л. Никулина. Методологические подходы к диагностике и прогнозированию развития региональных перспективных экономических специализаций

ях высокотехнологичных компаний, исследовательских центров, современной производственной и инновационной инфраструктуры [1].

Формирование теоретико-методологических основ конкурентоспособности регионов представлено в теориях: промышленных районов, промышленных округов, территориальных производственных систем, «полюсов конкурентоспособности», кластеров [2-6].

В современной российской науке и практике роли региональных экономических систем в конкурентоспособности национальной экономики также уделяется большое внимание. Значительный вклад в развитие данного направления научных исследований внесли работы Е. Г. Анимицы [7], А. Г. Гранберга [8], Е. С. Куценко [1, 9], Ю. Г. Лавриковой [10], П. А. Минакира [11], А. Н. Пилясова [12], А. И. Татаркина [13-15] и др. Концептуальные положения современной российской региональной экономической науки, касающиеся роли региональных экономических систем в обеспечении конкурентоспособности страны, в обобщенном виде сформулированы в работе [16]. «Для Российской Федерации в условиях глобальной интеграции и перехода к “новой экономике” эффективное и устойчивое развитие общей мегасистемы страны может быть обеспечено только на основе конкурентоспособности входящих в нее региональных экономических систем» [16]. В свою очередь, в соответствии с положениями современной экономической теории конкурентоспособность региона обеспечивается эффективным функционированием отраслей региональной специилизачии.

Для России актуальность развития методологических подходов к диагностике и прогнозированию развития региональных перспективных экономических специализаций в современных условиях обусловлена необходимостью выхода России на новые темпы экономического роста, что обеспечивается в том числе существенной трансформацией отраслевой специализации регионов с приоритетом высокотехнологичных отраслей.

Цель исследования: разработка методологических подходов к выделению существующих и потенциальных эффективных отраслей региональной специализации с учетом глобальных вызовов технологического развития. Комплекс научнblx задач включает определение условий, факторов, методов и механизмов трансформации региональных специализаций и формирования новых специализаций, отвечающих вызовам глобальных трендов технологического развития и учитывающих действие многовекторных факторов развития экономики региона.

\section{2 Проблемы современной региональной специализации: обзор литературы}

Региональная специализация имеет существенный теоретический базис. Значительный вклад в обоснование концепции региональной специализации внесли теории: абсолютных преимуществ (А. Смит) [17] и сравнительных преимуществ (Д. Рикардо) [18]. В ХX в. теория специализации в торговле представлена Э. Хекшером и Б. Олином [19]. Проблема региональной специализации и ее трансформации с позиций теории «полюсов конкурентоспособности» исследовалась французскими учеными [20].

На современном этапе региональная специализация рассматривается в теориях пространственной конкуренции, новой экономической географии, отраслевых рынков, позиционирования региона в конкурентной среде [16]. В последние 
15 лет значительное количество публикаций в зарубежной научной литературе посвящены вопросу трансформации отраслей специализации национальных экономик и региональных экономических систем в ходе диверсификации их отраслевой структуры, способствующей возникновению новых секторов экономики [21-23]. В исследовании Д. Форея, П. Давида, Б. Холла сформулирована концепция «умной специализации» $[24,25]$. Данная концепция в общем виде заключается в выявлении и развитии уникальных для экономики конкретного региона (страны) отраслей (видов экономической деятельности). В последующие годы концепция «умной специализации» получила свое развитие в работах западных экономистов, нашла широкое применение в экономической политике Евросоюза, была предложена Экспертной группой Европейской комиссии «Знание для роста» (Knowledge for Growth) в качестве стратегии инновационного развития регионов, основанной на наиболее эффективном использовании их особенностей, развитии конкурентных преимуществ [26].

В российской экономической науке вопросам региональной специализации уделяется значительное внимание. Исследование вопросов уровня региональной специализации, ее трансформации достаточно подробно рассматривается в работах Н. Н. Колосовского, Н. Н. Некрасова, Н. В Зубаревич, Е. Г. Анимицы, В. В. Акбердиной, Л. М. Гохберга, Е. А. Исланкиной, В. В. Кистанова, Н. В. Копылова, Е. С. Куценко, Н. Н. Михеевой, А. Н. Пилясова, О. А. Романовой и других ученых. Концепцию формирования в России новых региональных специализаций на принципах «умной специализации» развивают Е. С. Куценко [1, 9], В. Л. Абашкин [1], Е. А. Исланкина [1], А. Егорова [26] и ряд других исследователей [27].

Значительный интерес западной и отечественной науки к вопросу проблем региональных специализаций и касающихся подходов к разработке и внедрению в практику принципов «умной специализации» обусловлен, на наш взгляд, формированием запроса на новую модель регионального развития. С одной стороны, это обусловлено глобальными технологическими изменениями в современной экономике, формированием на их основе новых секторов экономики, внедрением цифровых технологий; с другой - исчерпанием традиционных источников экономического роста.

Исходя из указанных современных тенденций развития мировой экономики, А. Н. Пилясов [12] считает необходимостью ревизию классического определения региональной специализации (и, соответственно, формул ее расчета). А. Н. Пилясовым предложено следующее обобщающее классическое определение региональной специализации: «в классическом понимании региональная специализация - это доказанная на национальном уровне конкурентоспособность (жизнестойкость) одной отрасли или технологически сопряженного сочетания отраслей, которые формируют хозяйственный профиль данного региона» [12] и доказывается необходимость корректировки данного определения. Это связано с переходом от крупной специализациии (макроспециализации) к специализации меньшего уровня (в ряде случаев — к микроспециализации) в результате уменьшения (до уровня части региона) пространственного масштаба вызревания конкурентоспособной специализации и необходимостью оценки не только национального, но и глобального уровня конкурентоспособности для определения региональной специализации [12]. 
Л. М. Аверина, Н. Л. Никулина. Методологические подходы к диагностике и прогнозированию развития региональных перспективных экономических специализаций

А. Н. Пилясов констатирует, что ревизия классического определения региональной специализации требует, соответственно, корректировки формул ее расчета, поскольку прежние индикаторы и коэффициенты применяются к другому типу региональной хозяйственной специализации, соответствующему другому этапу развития экономики, и не в полной мере соответствуют современной эпохе [12]. В современной экономической науке существует множество методических подходов к определению отраслей специализации региона, использующих соответствующие показатели оценки уровня специализации. К числу наиболее известных и широко используемых в западной экономической литературе показателей относится коэффициент локализации $[28,29]$. Коэффициент локализации применяется для сравнения экономических характеристик отраслей (численность работников, объемы продаж и т. д.) на видовом, региональном, национальном уровнях. Величина данного коэффициента показывает доминирующую отраслевую специализацию предприятия, вида деятельности, региона [30]. На основе коэффициента (индекса) локализации был выведен ряд аналогичных коэффициентов, предназначенных для различных целей исследований, в том числе многочисленные показатели концентрации (индекс Херфиндаля - Хиршмана, индекс Холла - Тайдмена и др.). В последнее время в литературе отдается предпочтение показателям выявления сравнительных преимуществ и экономической сложности $[31,32]$ и другим.

В российской экономической науке нет единого подхода к идентификации отраслей специализации экономики региона. Большинство исследований базируются на двух концепциях - так называемой «вывозной», согласно которой важнейшим показателем уровня специализации является межрайонная товарность производимой продукции [33], и «производственной», основанной на роли показателя производства определенной продукции в регионе [34]. Следует отметить, что формулы расчета региональных специализаций, используемые в рамках указанных концепций, в ряде случаев не отражают реальную структуру экономики региона, так как исследователи оперируют неполной региональной информационной базой в связи с недостатками в системе российской государственной статистической отчетности. Конкретные примеры возможного искажения картины региональной специализации по этой причине приводятся в исследовании Е. С. Куценко, В. Л. Абашкина, Е. А. Исланкиной [1]. Например, авторы обращают внимание на то обстоятельство, что сведения об объеме отгруженной промышленной продукции по конкретному региону, содержащиеся форме статистической отчетности № П-1, приводятся по предприятиям и организациям, зарегистрированным в данном регионе, при этом не факт, что они в этом регионе осуществляют производственную деятельность. Таким образом, использование этих данных при расчете коэффициента локализации искажают картину региональной специализации. В исследовании также приводятся примеры другого порядка, когда ограниченность сведений, содержащихся в исходной статистической информации, затрудняет расчет коэффициентов межрайонной товарности, применяемых при определении уровня специализации той или иной отрасли в рамках «вывозной» концепции.

Современная экономика требует большего динамизма в структурных технологических и продуктовых изменениях, что в итоге содействует достижению успеха 
в инновационном поиске новой конкурентной специализации. Постоянное обновление региональных специализаций на основе технологических инноваций становится глобальным трендом мировой экономики [12]. Исследованию вопросов трансформации региональных специализаций посвящено значительное количество публикаций в зарубежной и отечественной научной литературе $[35,9]$.

\section{3 Методологический подход}

В современных условиях трансформация региональных специализаций происходит в условиях действия разновекторных факторов: с одной стороны, за счет технологических инноваций, которая может выражаться в создании новых отраслей специализации при ослаблении существующих отраслей, с другой - за счет действия элементов законсервированности существующих региональных специализаций [36]. Выделение перспективных региональных специализаций требует учета действия данных факторов.

В условиях наличия конкретных изменений в мировой и национальной экономике особую актуальность приобретают вопросы определения факторов, методов и механизмов трансформации региональных специализаций и формирования новых специализаций, отвечающих вызовам глобальных трендов технологического развития и учитывающих действие многовекторных факторов развития экономики региона.

Мировой и отечественный опыт показывает, что трансформация региональных специализаций осуществляется в ходе параллельно протекающих процессов:

1. Последовательная диверсификация существующих региональных отраслей специализации с изменением их структуры. Диверсификация осуществляется за счет:

- опережающего развития обрабатывающих производств с высокой долей добавленной стоимости;

- модернизации существующей отрасли с ее инновационным обновлением за счет внедрения перспективных технологий и активизации современных форм организации производства;

- появления новых наукоемких производств в составе существующих отраслей.

Следствием этого процесса является формирование новых конкурентоспособных секторов (далее, возможно, отраслей) региональной специализации, т. е. диверсификация с формированием новых отраслей специализации.

2. Возникновение в регионах в рамках существующей региональной специализации новых высокоэффективных производств не в региональном, а в территориальном формате.

Речь идет о новых производствах, размещаемых на территории технопарков, особых экономических зон, в кластерах и пр., деятельность которых при определенных условиях способствует формированию новой хозяйственной конкурентоспособной специализации региона. Таким образом, отмечает А. Н. Пилясов, на месте прежней региональной специализации вызревают атомарные новые микроспециализации уже не в региональном, а в городском, «местечковом» формате. Пространственный масштаб вызревания такой конкурентоспособной специализации становится мельче, чаще всего это часть региона, отдельный город, несколько муниципальных образований и т. д. [12]. По определению А. Н. Пиля- 
Л. М. Аверина, Н. Л. Никулина. Методологические подходы к диагностике и прогнозированию развития региональных перспективных экономических специализаций

сова, данный процесс является диверсификацией с созданием новых микроспециализаций на основе принципов «умной специализации [12]. Диверсификация по данному варианту обеспечивает формирование новых конкурентоспособных региональных микроспециализаций (с возможностью их трансформации, при наличии определенных условий, в отрасль специализации) за счет выявления для региона уникальной узкоспециализированной ниши на рынках высокотехнологичной продукции и современных технологий.

В исследованиях зарубежных и отечественных ученых предлагаются различные подходы к определению узкоспециализированной «ниши» для региональной экономики, учитывающие ее отраслевые особенности:

- наличие ключевых компетенций региона по выпуску высокотехнологичной продукции, конкурентоспособной на отечественном и мировом технологических рынках, созданной на основе перспективных технологий - аддитивные технологии, фотоника, нанотехнологии, промышленные биотехнологии и др.;

- применение ранее полученных результатов и готовых продуктов в приоритетных видах деятельности для повышения их эффективности [37];

- использование в качестве драйвера развития инноваций совмещение инженерных достижений с гуманитарной сферой (зеленая экономика). Данный подход, получивший в зарубежных исследованиях [38] название «эффект Гуггенхайма», используется в регионах, не обладающих значительным научным потенциалом и не имеющих заделы в развитии научных исследований в прорывных технологиях [39].

По нашему мнению, все рассмотренные подходы к определению «ниши» для региональных экономик объединяет следующее: признание необходимости выявления скрытых возможностей региона как в существующих отраслях специализации (с последующей концентрацией ресурсов на конкурентоспособных секторах), так и в смежных отраслях (секторах) экономики в сфере научных исследований. При этом недостаточно учитываются перспективы для «умной специализации», связанные с конвергенцией отраслей, и не принимаются во внимание возможности, предоставляемые развитием межрегионального взаимодействия и внешнеэкономических связей.

Таким образом, дальнейшие исследования, направленные на разработку методологических подходов к выбору приоритетов «умной специализации», инструментов и механизмов реализации в целях ее адаптации в условиях России, представляют несомненный научный и практический интерес.

Для России проблема трансформации региональных специализаций чрезвычайно актуальна, поскольку выход на новые темпы и качество экономического роста с реализацией модели экономики инновационного развития обеспечивается в том числе трансформацией отраслевой специализации экономики страны и ее регионов, формированием новых быстро развивающихся секторов экономики. В Стратегии пространственного развития Российской Федерации на период до 2025 г. (далее - Стратегия) перед регионами поставлена задача повышения конкурентоспособности за счет трансформации отраслевой структуры на основе ускоренного развития перспективных отраслей эффективной специализации.

В связи с постановкой данной задачи на федеральном уровне становится особенно актуальным исследование вопросов выделения региональных перспектив- 
ных специализаций. В Стратегии определены перспективные экономические специализации для всех субъектов РФ, и данный перечень подвергся критике со стороны научного сообщества. Серьезные вопросы вызывает обоснованность отнесения обозначенных в Стратегии отраслей к перспективной экономической специализации регионов. Их перечень, представленный в Стратегии для каждого из субъектов РФ, является достаточно обширным, при этом он включает не только реально и потенциально перспективные, но практически все существующие в данных субъектах РФ отрасли экономики. Данный перечень сложно признать рациональным, и тем более сбалансированным, поскольку при значительном количестве позиций отсутствует комплексность. Кроме того, в большинстве случаев не учитываются специфика хозяйственного комплекса конкретного региона, масштаб и интенсивность текущих структурных изменений в его экономике. В современных исследованиях отечественных экономистов предлагаются различные подходы к выделению перспективных отраслей эффективной специализации региональных экономик, которые в обобщенном виде формируют определенный алгоритм их выделения [40, 41]:

1. Идентификация новых глобальных трендов технологического развития в отраслях текущей и потенциальной региональной специализации.

2. Выявление перспективных технологий, обладающих потенциалом формирования новых секторов экономического роста, и определение области их внедрения в отраслях экономики региона.

3. Выявление новых сегментов экономики знаний с потенциалом востребованности в отраслях текущей и перспективной региональной специализации. Учет перспективы конвергенции в сфере научных исследований. Определение формата объединения усилий науки, бизнеса, власти (технопарк, кластер, ОЭЗ) и др.) для развития производства высокотехнологичной продукции и передовых технологий в рамках отдельной узкоспециализированной ниши, определенной с использованием принципов «умной специализации».

4. Идентификация региональных перспективных специализаций с учетом их потенциального места на общенациональном рынке товаров и технологий. Оценка не только национального, но и глобального уровня конкурентоспособности для отраслей и секторов региональной экономики, имеющих выход на внешние (в т. ч. мировые) рынки, с использованием индекса Херфиндаля - Хиршмана, индекс Баласса и других показателей, позволяющих оценить их позиционирование и конкурентные преимущества на глобальных рынках.

\section{4 Результаты исследования}

Результатом выполненного исследования, определяющим его научную новизну, являются следующие выводы:

Соглашаясь с представленными подходами к выделению перспективных экономических специализаций региона, считаем необходимым дополнительно учесть в алгоритме выделения перспективных экономических специализаций региона следующие шаги:

1) на начальном этапе исследования осуществлять вариативный анализ особенностей формирования новых конкурентных отраслей специализации в соответствии с типами регионов (индустриальный, аграрный, ресурсный и т. д.), раз- 
Л. М. Аверина, Н. Л. Никулина. Методологические подходы к диагностике и прогнозированию развития региональных перспективных экономических специализаций

личающихся по производственному, инновационному, научному потенциалам, научно-технологической и отраслевой специализации;

2) на всех этапах исследования производить оценку технологической «связанности», наличия сквозных технологий межотраслевого значения на предприятиях, дислоцированных в разных регионах РФ, и возможной перспективы углубления их кооперационного взаимодействия.

Практическая значимость выполненного исследования заключается в следующем. Предлагаемый алгоритм выделения перспективных экономических специализаций, основанный на сочетании имеющихся научных подходов к решению проблемы и учитывающий региональные особенности и потенциал межрегионального взаимодействия, может быть рекомендован для формирования перечня перспективных экономических специализаций конкретного субъекта РФ. Это позволит определить перспективный отраслевой профиль региона как основы для выбора экономических приоритетов его развития и разработки наиболее эффективной модели регионального развития.

\section{Заключение}

Научно обоснованное определение перспективных региональных специализаций обеспечит перспективное видение внутренних возможностей регионального роста, основанное на существующих и потенциальных конкурентных преимуществах региона. Это, в свою очередь, позволит оценить перспективы трансформации хозяйственной структуры региона за счет структурных и технологических изменений, обеспечивающих укрепление рыночных позиций на мировом и внутреннем рынке, оценить потенциал межрегионального взаимодействия и повышения степени интегрированности экономического пространства России на этой основе.

\section{Благодарность}

Статья подготовлена в соответствии с Планом НИР для Лаборатории моделирования пространственного развития территорий Института экономики УрО РАН на 2021 год.

\section{Литература}

1. Куценко Е. С., Абашкин В. Л., Исланкина Е. А. Фокусировка региональной промышленной политики через отраслевую специализацию // Вопросы экономики. 2019. №5. C. 65-89.

2. Innovation - driven growth in regions. The role of smart specialization. Paris: OECD Publishing, 2013. 202 p. URL: https://www.oecd.org/innovation/inno/ smahttps://www.oecd.org/innovation/inno/smart-specialisation.pdfrt-specialisation.pdf (Date of access: 30.12.2020).

3. Frenken K., Yan Oort F., Verburg T. Related variety, unrelated variety and regional economic growth // Regional studies. 2007. Vol. 41, no. 5. P. 665-697.

4. Edmondson G., McCollam S., Kelly E. 5 Steps to Smarter Specialisation. A briefing note on innovation investments to be made under the European Commission's new cohesion policy. Brussels: Science Business Publishing Ltd, 2014. URL: http://knowhub.eu/static/global/media_catalog/2014/03/28/193/original.pdf (Date of access: 30.12.2020).

5. Capello R., Lenzi C. Territorial patterns of innovation: A taxonomy of innovative regions in Europe // The Annals of Regional Science. 2013. Vol. 51, no. 1. P. 119-154. 
6. Портер М. Международная конкуренция. М.: Международные отношения, 1993. 896 с.

7. Регион в социально-экономическом пространстве России: анализ, динамика, механизм управления / Е. Г. Анимица [и др.]. Пермь, 2008. 377 с.

8. Гранберг А. Г. Основы региональной экономики. М.: ГУВШЭ, 2006. 495 с.

9. Куценко Е., Еферин Я. «Водовороты» и «тихие гавани» в динамике отраслевой специализации регионов России // ФОРСАЙТ. 2019. Т. 13, № 3. С. 24-40. DOI: 10.17323/2500-2597.2019.3.24.40

10. Лаврикова Ю. Г., Акбердина В. В., Суворова А. В. Согласование приоритетов научно-технологического и пространственного развития индустриальных регионов // Экономика региона. 2019. Т. 15, вып. 4. C. 1022-1035. DOI: 10.17059/2019-4-5.

11. Минакир П. А. Пространственные трансформации в российской экономике. М.: Экономика, 2002. 424 с.

12. Пилясов А. Н. Региональная инвестиционная политика: как преодолеть «зависимость от пути // Регион: экономика и социология. 2018. №4. С. 134-167.

13. Конкурентоспособность региона: новые тенденции и вызовы / под ред. А. И. Татаркина. Екатеринбург: Изд-во УрО РАН, 2003. 208 с.

14. Регион в новой парадигме пространственной организации России / под ред. А. И. Татаркина. М.: Экономика, 2007. 752 с.

15. Прогнозирование социально-экономического развития региона / под ред. В. А. Черешнева, А. И. Татаркина, С. Ю. Глазьева. Екатеринбург: Изд-во ИЭ УрО РАН, 2011. 1104 с.

16. Карпенко С. В., Силина Т. А., Ордынская М. Е. Системный подход к исследованиям мезоуровня экономических отношений в региональных экономических системах // Эффективная экономика современности: в 2 кн. / под общ. ред. С. В. Куприенко; SWorld. Одесса, 2012. 186 с. С. 79-92.

17. Смит А. Исследование о природе и причинах богатства народов. М.: Эксмо, 2007. 960 c.

18. Рикардо Д. Сочинения. Т. 1. Начала политической экономии и налогообложения. М.: Гос. изд-во полит. лит-ры, 1955. 360 с.

19. Хекшер. Э. Влияние внешней торговли на распределение дохода. Вехи экономической мысли. М.: Экономическая школа, 2006. Т. 6. 720 с.

20. Aglietta M., Boyer R. Poles de competitivite, strategie industrielle et politique macroeconomique. Paris: Working paper CEPREMAP № 8223. 1982. 61 p. URL: http://www.cepremap.fr/depot/couv_orange/co8223.pdf (Date of access: 30.12.2020).

21. Hidalgo C. A., Hausmann R. The building blocks of economic complexity // Proceedings of the National Academy of Sciences (PNAS). 2009. June 30. Vol. 106, no. 26. P. 1057010575.

22. Boschma R. Relatedness as driver of regional diversification: A research agenda // Regional Studes. 2017. Vol. 51, no. 3. P. 351-364.

23. Chen J. Interpreting economic diversity as the presence of multiple specializations. RRI Working Paper 2018-02. Morgantown, WV: West Virginia University, 2018. 24 p. URL: https://pdfs.semanticscholar.org/fdd5/8db09e249dc9149c8e960bd 4b3c90f732976.pdf?_ga=2.201326446.1178166882.1591678083-1342558215.159167 8083 (Date of access: 30.12.2020).

24. Foray D. Smart Specialization and the New Industrial Policy Agenda. Paper presented at the 2013 ERAC Mutual Learning Seminar, 20th March 2013. URL: https://era.gv.at/object/document/360/attach/industrial_policy_agenda.ppt (Date of access: 30.12.2020).

25. Foray D., David P., Hall B. Smart specialization - The concept. Knowledge for Growth: Prospects for science, technology and innovation, Report, EUR 24047, European Union, 2009. 84 p. P. 25-30. URL: https://www.kowi.de/Portaldata/ 2/Resources/fp/reportknowledge-for-growth.pdf (Date of access: 30.12.2020). 
Л. М. Аверина, Н. Л. Никулина. Методологические подходы к диагностике и прогнозированию развития региональных перспективных экономических специализаций

26. Егорова А. «Умная специализация» - новый виток кластерной политики. URL: https://oecd-russia.org/analytics/umnaya-spetsializatsiya-novyj-vitok-klasternoj-politiki.html (дата обращения: 30.12.2020). Текст : электронный.

27. Smirnova O. P., Averina L. M., Ponomareva A. O. Transformation of industries in the conditions of new technological challenges // Advances in Systems Science and Applications. 2020. Vol. 20, is. 3. P. 36-49. DOI: 10.25728/assa.2020.20.3.851.

28. Porter M. Location, competition, and economic development: local clusters in a global economy // Economic Development Quarterly. 2000. Vol. 14, is. 1. P. 15-34.

29. Fracasso A., Marzetti G. V. Estimating dynamic localization economies: The inadvertent success of the specialization index and the location quotient. Regional Studes. 2018. Vol. 52. P. 119-132.

30. Гаращенко Е. А. Методика определения коэффициента локализации и эффективной защиты внешней торговли // Вестник Белорусского государственного экономического университета. 2014. № 6. C. 12-16.

31. Hausmann R., Klinger B. Structural transformation and patterns of comparative advantage in the product space, CID Working Papers, No. 128. Center for International Development at Harvard University, 2006. 38 p. URL: https:/growthlab.cid.harvard.edu/files/ growthlab/files/128.pdf (Date of access: 30.12.2020).

32. Hidalgo C., Hausmann R. The building blocks of economic complexity // Proceedings of the National Academy of Sciences. 2009. Vol. 106. P. 10570-10575.

33. Прокопьев Е. А. К вопросу о выборе данных для определения специализации региона // Друкеровский вестник. 2015. № 2. С. 236-245.

34. Белов А. В. К вопросу о пространственном размещении факторов производства в современной России // Пространственная экономика. 2012. № 2. С. 9-28.

35. The product space conditions the development of nations / C. A. Hidalgo, B. Klinger, A.-L. Barabasi, R. Hausmann // Science. 2007. Vol. 317. P. 482-487.

36. Brezis E. S., Krugman P. R., Tsiddon D. Leapfrogging in international competition: A theory of cycles in national technological leadership // American Economic Review. 1993. Vol. 83, no. 5. P. 1211-1219.

37. Kutsenko E., Islankina E., Kindras A. Smart by Oneself? An Analysis of Russian Regional Innovation Strategies within the RIS3 Framework // Foresight and STI Governance. 2018. Vol. 12, no. 1. P. 25-45. DOI: 10.17323/2500-2597.2018.1.25.45.

38. Vicario L., Monje P. Another «Guggenheim Effect»? The generation of a potentially gentrifiable neighbourhood in Bilbao // Urban Studies. 2003. Vol. 40, no. 12. P. 2383-2400.

39. Коровин Г. Б., Аверина Л. М. Развитие «зеленой экономики» на принципах «умной специализации» // Экономика природопользования. 2019. № 6. С. 18-27.

40. Эдер Л. В., Саблин К. С., Проворная И. В. Научные подходы к обоснованию приоритетных инновационно-технологических направлений пространственной специализации ресурсных регионов России // Фундаментальные исследования. 2017. №5. С. 220224. URL: http://fundamental-research.ru/ru/article/view?id=41538 (дата обращения: 30.12.2020). Текст : электронный.

41. Земцов С. П., Баринова В. А. Смена парадигмы региональной инновационной политики в России: от выравнивания к «умной специализации». URL: www institutiones.com/innovations/2920-smena-paradigmy-regionalnoi-innovacionnoi-politiki-rossii.html (дата обращения: 30.12.2020). Текст : электронный.

Статья поступила в редакцию 30.12.2020; одобрена после рецензирования 28.01.2021; принята к публикации 29.01.2021. 


\title{
METHODOLOGICAL APPROACHES TO DIAGNOSIS \\ AND FORECASTING OF THE DEVELOPMENT OF PROMISING REGIONAL ECONOMIC SPECIALIZATIONS
}

\author{
Lidiya M. Averina \\ Junior Researcher \\ laverina@mail.ru
}

Natalia L. Nikulina

Cand. Sci. (Econ.), Senior Researcher

nikulinanl@mail.ru

Institute of Economics, Ural Branch of RAS

29 Moskovskaya St., Ekaterinburg 620014, Russia

Abstract. The article present an argument for developing new industries of regional specialization, taking into account the global challenges of technological development. The study hypothesis is based on the assumption of the important role of promising effective regional economic specializations in the transformation of regional economic structure, which by means of innovative technologies provides a new quality of economic growth, increased integration into the Russian economic space. We have analyzed the main approaches to determining the role of regional economies in ensuring the country's competitiveness, emphasized the importance of "smart specialization" in forecasting the development of promising regional economic specializations. For identification of the promising economic specializations it is necessary to make a variable-based analysis of the development features of new competitive industries of specialization in accordance with the types of regions; to assess the availability of end-to-end technologies of cross-sectoral significance at enterprises located in different regions of the Russian Federation, and the possible prospects for their cooperation. Keywords: industries of regional specialization; regional promising economic specializations; competitiveness; "smart specialization"; diagnosis; forecasting; "niches” of regional economy; interregional interaction. 